\title{
Evaluation of neutron cross sections for hafnium in the resolved resonance range
}

DOI:

10.3938/jkps.59.1884

Link to publication record in Manchester Research Explorer

\section{Citation for published version (APA):}

Ware, T., Weaver, D., Moxon, M., Dean, C., Hiles, R., Schillebeeckx, P., \& Kopecky, S. (2011). Evaluation of neutron cross sections for hafnium in the resolved resonance range. In Journal of the Korean Physical Society|J. Korean Phys. Soc. (Vol. 59, pp. 1884-1887). Korean Physical Society. https://doi.org/10.3938/jkps.59.1884

\section{Published in:}

Journal of the Korean Physical Society|J. Korean Phys. Soc.

\section{Citing this paper}

Please note that where the full-text provided on Manchester Research Explorer is the Author Accepted Manuscript or Proof version this may differ from the final Published version. If citing, it is advised that you check and use the publisher's definitive version.

\section{General rights}

Copyright and moral rights for the publications made accessible in the Research Explorer are retained by the authors and/or other copyright owners and it is a condition of accessing publications that users recognise and abide by the legal requirements associated with these rights.

\section{Takedown policy}

If you believe that this document breaches copyright please refer to the University of Manchester's Takedown Procedures [http://man.ac.uk/04Y6Bo] or contact uml.scholarlycommunications@manchester.ac.uk providing relevant details, so we can investigate your claim.

\section{OPEN ACCESS}




\title{
Evaluation of Neutron Cross Sections for Hafnium in the Resolved Resonance Range
}

\author{
T. WARE and D. WEAVER \\ School of Physics and Astronomy, University of Birmingham, Edgbaston, Birmingham, B15 2TT, UK \\ M. MOXON \\ 3 Hyde Copse, Marcham, Oxfordshire, OX13 6PT, UK \\ C. DEAN* and R. HILES \\ Serco, Kimmeridge House, Dorset Green Technology Park, \\ Winfrith Newburgh, Dorchester, Dorset DT2 8ZB, UK \\ P. SCHILLEBEECKX and S. KOPECKY \\ EC-JRC-IRMM, B-2440 Geel, Belgium
}

(Received 26 April 2010)

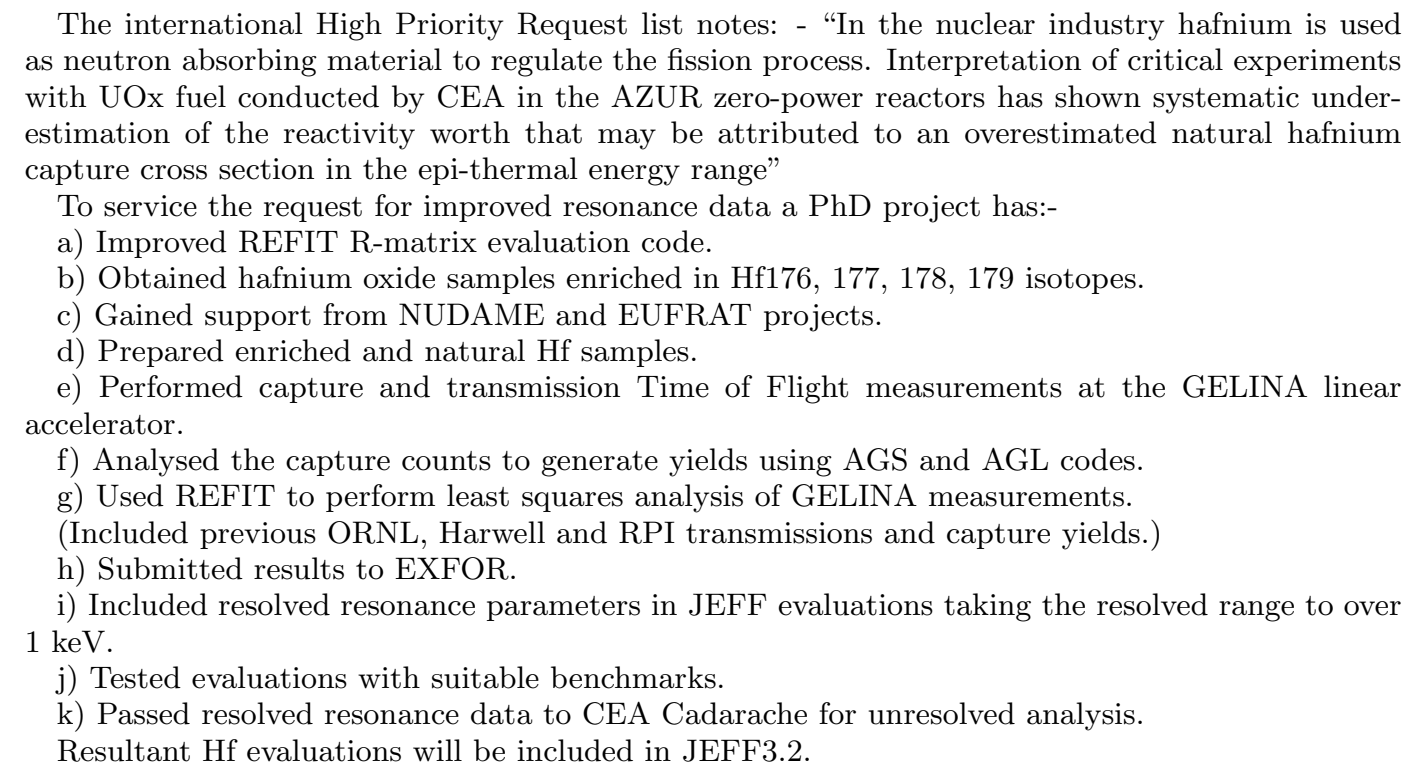

PACS numbers: 25.40.-h, 28.60.+s

Keywords: ND2010, Nuclear data, JEFF, Hafnium, REFIT, GELINA

DOI: $10.3938 /$ jkps.59.1884

\section{INTRODUCTION}

The large absorption cross-section of hafnium makes it a candidate for use in reactor control rods to regulate the fission process. As it is a resonance absorber, it is favoured for use in thermal fission reactors with harder neutron spectra, such as those using MOX fuel. Hence, it is important to understand the hafnium cross-section in the resolved resonance energy range.

*E-mail: christopher.dean@serco.com
Calculations on the AZUR criticality experiments conducted by CEA, using the latest JEFF3.1 isotopic hafnium evaluations based on recent RPI measurements [1], indicate a measured rod worth of $7000 \mathrm{pcm}$ being out by $\sim 30 \mathrm{pcm}[2]$. This may be due to an overestimate of the natural hafnium capture cross section. Resonances below $\sim 180 \mathrm{eV}$ are reasonably defined by recent measurements at RPI [2]. Above $\sim 250 \mathrm{eV}$ unresolved resonances are present in JEFF3.1. The Hf isotope files can be improved by extending the resolved resonance range to higher energies, thereby negating uncertainties 
Table 1. Hafnium Enrichments.

\begin{tabular}{cccccc}
\hline \hline Isotope & ${ }^{176} \mathrm{Hf}$ & ${ }^{177} \mathrm{Hf}$ & ${ }^{178} \mathrm{Hf}$ & ${ }^{179} \mathrm{Hf}$ & ${ }^{180} \mathrm{Hf}$ \\
\hline${ }^{176} \mathrm{Hf}$ & $\mathbf{6 5 . 0}$ & 22.9 & 6.3 & 1.8 & 4.0 \\
${ }^{177} \mathrm{Hf}$ & 1.0 & $\mathbf{8 5 . 4}$ & 11.3 & 0.9 & 1.4 \\
${ }^{178} \mathrm{Hf}$ & 0.8 & 1.9 & $\mathbf{9 2 . 4}$ & 3.3 & 1.6 \\
${ }^{179} \mathrm{Hf}$ & 0.2 & 1.3 & 4.1 & $\mathbf{7 2 . 1}$ & 22.3 \\
\hline \hline
\end{tabular}

from the treatment of the unresolved resonance range. Ideally, this objective can be achieved through capture cross-section measurements on hafnium identified on the NEA Nuclear Data High Priority Request List [3].

\section{NUDAME AND EUFRAT PROJECTS}

The EUFRAT [4] project and predecessor NUDAME offer opportunities for researchers to access EC-JRCIRMM accelerator facilities. Approved requests for $\mathrm{Hf}$ measurements allowed visits in 2007-2009 to measure Hf samples on the GELINA LINAC [5].

\section{EXISTING MEASUREMENTS}

The JEFF3.1 evaluation for Hf includes resolved resonance parameters from Trbovich [1]. His thesis reviews the status of Hf measurements prior to RPI's natural metal and enriched solution transmission and capture measurements. It highlights early transmission measurements by Harvey [6] plus capture and transmission measurements by Moxon [7]. All three authors kindly supplied transmissions/yields for potential inclusion in EXFOR [8]. Noguère [9] considers more recent cold and room temperature transmission measurements by Siegler [10]. Study of all these indicated the importance of using isotopically enriched samples to allocate resonances to isotopes.

\section{ENRICHED SAMPLES}

Isotopically enriched samples were kindly loaned by INRNE Sofia [11]. The \% enrichments of the Hf in the $\mathrm{HfO}_{2}$ samples are given in Table 1. The samples were in thin walled aluminium cans. In all cases, ${ }^{174} \mathrm{Hf}$ was less than $0.05 \%$ abundant.

\section{EXPERIMENTAL SETUP}

The IRMM GEel pulsed LINear Accelerator (GELINA) [5] operates at frequencies of between 50 and $800 \mathrm{~Hz}$. A compressed pulse of electrons with a width of $\sim 1$ nanosecond strikes the rotating uranium target. The resulting Bremsstrahlung radiation produces a fission-like neutron spectrum via $(\gamma, \mathrm{n})$ and $(\gamma, f)$ reactions in the uranium. The fast neutrons are moderated by two adjacent water-filled beryllium containers to give neutrons at energies between $\sim 1 \mathrm{meV}$ and $\sim 20 \mathrm{MeV}$. These moderated pulsed neutrons are collimated into beams down the 12 flight paths arranged around the target. Stability and intensity are monitored by two $\mathrm{BF}_{3}$ proportional counters.

Capture measurement stations are positioned at the 10, 30 and $60 \mathrm{~m}$ flight paths with interstitial fixed antioverlap filters $\left({ }^{10} \mathrm{~B}\right.$ or $\left.{ }^{\text {nat }} \mathrm{Cd}\right)$ and changeable background filters (Ag, Bi, Co, Na, S, and $\mathrm{W})$. The $\gamma$-rays originating from the capture reaction are detected with $\mathrm{C}_{6} \mathrm{D}_{6}$-based liquid scintillators [12] of $10 \mathrm{~cm}$ diameter and $7.5 \mathrm{~cm}$ height. Capture events, and neutron time-of-flight, determined using the IRMM Fast Time Digitizer [13] with a 0.5 ns resolution, were recorded on the Geel DAC2000 data acquisition system [14].

\section{GEEL MEASUREMENTS}

In April 2007, GELINA was used at $50 \mathrm{~Hz}$ to measure $0.026,0.079$ and $0.024 \mathrm{~mm}$ thick natural Hf samples at the $12.89 \mathrm{~m}$ measurement station. In October 2007, a $1 \mathrm{~mm}$ natural sample was measured at $800 \mathrm{~Hz}$ in the $58.586 \mathrm{~m}$ station introducing a ${ }^{10} \mathrm{~B}$ overlap filter. In 2008, the enriched samples were prepared and ${ }^{177} \mathrm{Hf}$ (thickness $3.223 \mathrm{~mm} / 1.91 \times 10^{-3}$ atoms/barn), ${ }^{178} \mathrm{Hf}\left(2.502 / 1.80 \times 10^{-3}\right),{ }^{178} \mathrm{Hf}\left(1.052 / 0.82 \times 10^{-3}\right)$, ${ }^{179} \mathrm{Hf}\left(2.452 / 2.14 \times 10^{-3}\right)$ and ${ }^{n a t} \mathrm{Hf}(1.081 / 4.5953 \times$ $\left.10^{-3}\right)$ measurements were made at $800 \mathrm{~Hz}$ on the 12.95 $\mathrm{m}$ station retaining the ${ }^{10} \mathrm{~B}$ filter. Next, the $28.82 \mathrm{~m}$ station was used to measure ${ }^{176} \mathrm{Hf}\left(2.062 / 2.17 \times 10^{-3}\right)$, ${ }^{177} \mathrm{Hf}\left(3.223 / 1.91 \times 10^{-3}\right),{ }^{178} \mathrm{Hf}\left(2.502 / 1.80 \times 10^{-3}\right)$, ${ }^{179} \mathrm{Hf}\left(2.452 / 2.14 \times 10^{-3}\right)$ and ${ }^{\text {nat }} \mathrm{Hf}(1.081 / 4.5953 \times$ $10^{-3}$ ) at $800 \mathrm{~Hz}$ with ${ }^{10} \mathrm{~B}$ filter. In October $2008,{ }^{176} \mathrm{Hf}$ $\left(2.062 / 2.17 \times 10^{-3}\right)$ and ${ }^{179} \mathrm{Hf}\left(2.452 / 2.14 \times 10^{-3}\right)$ measurements were made at $50 \mathrm{~Hz}$ on the same station but with ${ }^{\text {nat }} \mathrm{Cd}$ filters. In all cases, the incident neutron flux was continuously measured with a ${ }^{10} \mathrm{~B}$ ionisation chamber placed $\sim 1 \mathrm{~m}$ in front of the sample. The measurements were designed to optimise counts from $0.1 \mathrm{eV}$ to several keV. Finally a thick $\left(16 / 6.893 \times 10^{-2}\right)$ natural Hf sample was measured at the $49.34 \mathrm{~m}$ station with

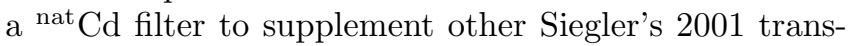
mission measurements [10] and to help understand some resolution problems and check the nuclei radii used in the analysis. As well as the main measurements, ancillary measurements were made with various filters present to deduce the background count.

\section{ANALYSIS OF THE MEASUREMENTS}

The Analysis of Geel List-mode (AGL) code package [15] was used to bin the raw measurement data into 30720 variable width time-of-flight channels to cover the full energy range in sufficient detail. Each measurement is performed over a number of one hour cycles and AGL rejects any cycles with unstable beam conditions. It checks all results are meaningful relative to known crite- 
ria regarding apparatus used. The code then outputs a spectrum (histogram) of reliable counts for each detector used in the measurement.

The Analysis of Geel Spectra (AGS) code package [16, 17] performs a dead time correction for each detector spectrum and merges them to form a single spectrum. This operation was repeated for the flux detectors and uncertainties in both are formed. Using the black resonances in the ancillary measurements, the time dependence of the background was manually fitted for both the capture and flux measurements. The capture spectrum is then divided by the flux spectrum after alignment. The resultant yields were normalised using the saturated, low energy ${ }^{177} \mathrm{Hf}$ resonances and will be available in EXFOR [8].

\section{STABILISATION OF THE REFIT CODE}

REFIT is a widely used Least-Square Fitting Program for Resonance Analysis of Neutron Transmission, Capture, Fission and Scattering Data. REFIT-2007 was consolidated during the initial Hf analysis. The code was then used at a summer school in Geel in 2008 and further modification suggested before application to the final analysis as REFIT-2009 [18].

\section{EVALUATION}

The resonance analysis of the measured hafnium was performed in several stages. The allocation of resonances was primarily performed by overlaying plots of the capture yields from the Geel $30 \mathrm{~m}$ measurements of the enriched oxide and natural $1 \mathrm{~mm}$ foil hafnium samples, plus Moxon's enriched sample measurements [7], particularly for ${ }^{180} \mathrm{Hf}$. This process is demonstrated in Fig. 1 where a doublet in ${ }^{177} \mathrm{Hf}$ overlying a single ${ }^{179} \mathrm{Hf}$ resonance is replaced by doublets in both isotopes.

Using resonances in JEFF3.1 and ENDF/B-VI.8 evaluations, plus the new resonances, prior sets of resonance parameters evolved during the fitting process.

For ${ }^{177} \mathrm{Hf}$ and ${ }^{179} \mathrm{Hf}$, where there are two possible swave resonance spins for each isotope, the spin value was arbitrarily assigned such that the distribution between the two spin values was approximately equal.

REFIT needs experimental parameters input. An effective temperature of $302.9 \mathrm{~K}$ was applied. The efficiency for the detection of neutron capture in a given isotope is proportional to the binding energy for the $\mathrm{C}_{6} \mathrm{D}_{6}$ detectors. Isotopic efficiencies were formed, relative to unity in ${ }^{177} \mathrm{Hf}$, (including accounting for capture to the meta-stable state in ${ }^{179} \mathrm{Hf}$ ). Quoted flight path lengths were adjusted by REFIT and the resultant values used. In the analysis of the capture, an energy dependent scattered neutron detection efficiency was included. Nuclear parameters for impurities, canning and sample holders were also included ( $\mathrm{Zr}, \mathrm{O}, \mathrm{Al}, \mathrm{Br}, \mathrm{Mn}$ ).

Average capture widths for each isotope were determined from a weighted average of fitted capture widths

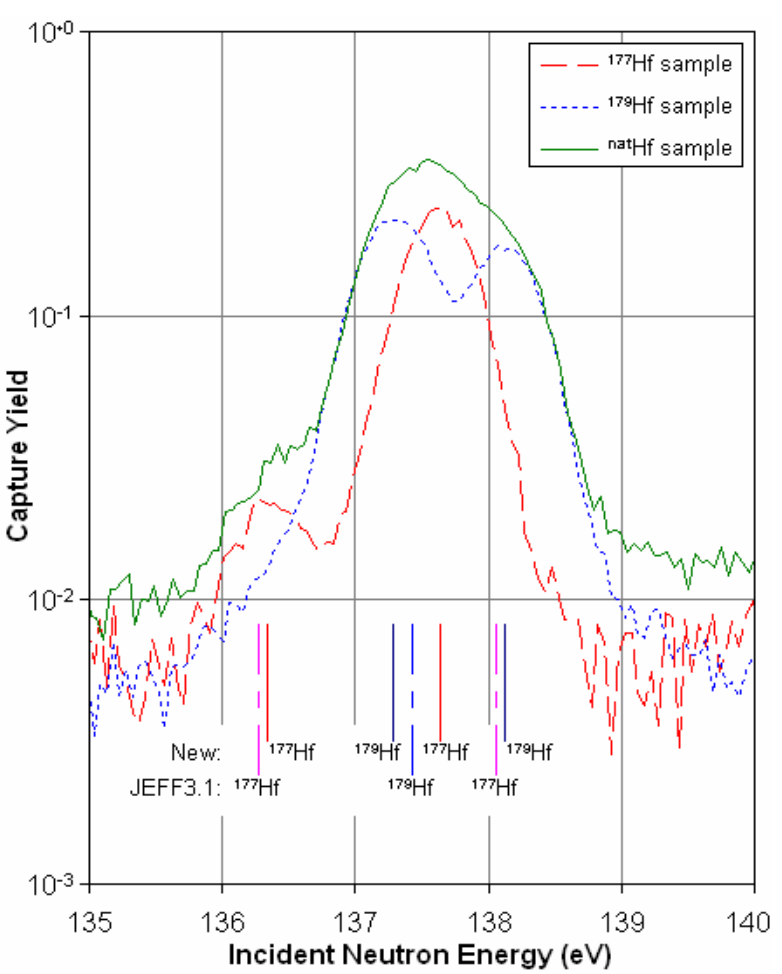

Fig. 1. (Color online) Comparison of capture yield curves of Hf sample measurements with resonance allocation from JEFF3.1 (long markers) and this work (short markers).

for that isotope. For resonances in the even-mass isotopes, they were used where $\Gamma_{\mathrm{n}}$ was much less than $\Gamma_{\gamma}$. They were used for all ${ }^{177} \mathrm{Hf}$ and ${ }^{179} \mathrm{Hf}$ resonances above $50 \mathrm{eV}$ and for resonances below $50 \mathrm{eV}$ where the resonance area was deemed insensitive to $\Gamma_{\gamma}$. In other cases individual $\Gamma_{\gamma}$ 's were treated as variables but it was found that if the calculation was insensitive to the parameter, the "fitted" value would differ with each run of REFIT without converging to any one value and have a high uncertainty associated with it and potentially be very different to the starting (JEFF3.1) value. This had to be manually detected.

Hafnium resonance parameters for the $0.5 \mathrm{eV}$ to $1 \mathrm{keV}$ neutron energy range were derived by the simultaneous analysis in $\sim 50 \mathrm{eV}$ energy segments of several measurement data sets using the REFIT code.

Re-analysis of RPI's measurements using isotopicallyenriched solution samples derived different parameters for the $7.8 \mathrm{eV}$ doublet [19]. Using these as fixed input, resonance parameters within the $0.5-20 \mathrm{eV}$ neutron energy range were derived using the Geel 12 $\mathrm{m}$ oxide and $1 \mathrm{~mm}$ metal capture measurement data, together with the RPI transmission measurements of $0.001,0.002,0.004,0.010,0.020$ and 0.050 inch natural hafnium metallic samples. Published thermal capture cross sections were reviewed, adjusted to modern standards and the inverse variance weighted results used to calculate bound levels; the REFIT run was repeated. The resonance parameters of $20-1000 \mathrm{eV}$ energy range 
Table 2. Resolved Resonance Statistics.

\begin{tabular}{ccccc}
\hline \hline & \multicolumn{2}{c}{ RR Top limit (eV) } & \multicolumn{2}{c}{ No. Resonances in RR } \\
\cline { 2 - 5 } & JEFF3.1 & New file & JEFF3.1 & New file \\
\hline${ }^{174} \mathrm{Hf}$ & 220 & 250 & 12 & 14 \\
${ }^{176} \mathrm{Hf}$ & 700 & 3000 & 19 & 74 \\
${ }^{177} \mathrm{Hf}$ & 250 & 1000 & 94 & 331 \\
${ }^{178} \mathrm{Hf}$ & 1500 & 3000 & 23 & 55 \\
${ }^{179} \mathrm{Hf}$ & 250 & 1000 & 50 & 219 \\
${ }^{180} \mathrm{Hf}$ & 2500 & 3000 & 16 & 21 \\
\hline \hline
\end{tabular}

were derived using the Geel capture yield data, together with the $16 \mathrm{~mm}$ natural Hf transmission measurement and those of Siegler [10]. The Geel $12 \mathrm{~m}$ capture data were not used above $250 \mathrm{eV}$ due to poor experimental resolution.

The quality of the fit for a segment was assessed by visual inspection of the fitted curve relative to the experimental data, using REFIT's graphical output, the $\chi^{2}$ values for individual data sets and the overall $\chi^{2}$ value for the run.

At neutron energies around $1 \mathrm{keV}$, the experimental resolution and Doppler effects mean that the closely spaced ${ }^{177} \mathrm{Hf}$ and ${ }^{179} \mathrm{Hf}$ resonances cannot be resolved, but broad resonances of ${ }^{176} \mathrm{Hf},{ }^{178} \mathrm{Hf}$ and ${ }^{180} \mathrm{Hf}$ are still resolvable to around $3 \mathrm{keV}$. Further analysis of the $1-3$ $\mathrm{keV}$ neutron energy range took place within these constraints. Unfortunately, features in the Beer and Macklin $[20,21]$ evaluation could not be seen in Geel measurements preventing use of their data at higher energies.

\section{RESONANCE PARAMETERS}

Resonance parameters in ENDF6 format were concatenated for each isotope and used to replace parameters in the current JEFF3.1 files giving the statistics in Table 2 .

\section{TESTING}

The new evaluations have been applied using the MONK Monte-Carlo code [22] to assess two integral benchmarks containing different size Hf blocks within enriched fuel. K-eff was reduced by $100 \mathrm{pcm}$ for the case with the small block and $160 \mathrm{pcm}$ for the large block leaving it supercritical by $100 \mathrm{pcm}$. Further study indicated improvement to be due to addition of resonances above $250 \mathrm{eV}$.

\section{CONCLUSION}

New Hf resolved resonance evaluations have been generated and submitted to JEFF. Although our initial test- ing yields an improved prediction, a reduction in K-eff seems contrary to the initial indication in the request list. We await with interest the CEA's findings but also note we are reducing the resonance integral yet increasing absorption at higher energies due to adding resonances. A PhD thesis will fully describe the work [23].

\section{ACKNOWLEDGMENTS}

The authors would like to thank other scientists at Geel, RPI, ORNL, INRNE and Cadarache for support.

\section{REFERENCES}

[1] M. J. Trbovich, Ph.D, thesis, 2003.

[2] G. Noguère et al., JEFDOC-1077, 2005.

[3] NEA High Priority Request List: http://www.nea.fr/html/dbdata/hprl/index.html.

[4] EUFRAT JRC Web Page: http://irmm.jrc.ec.europa.eu $/ \mathrm{html} /$ activities/eufrat/index.htm.

[5] A. Borella et al., in Proceedings of the Inter. Conf. on Nucl. Data for Sci. and Techn.(ND2007) (Nice, Frannce, 2007).

[6] T. Fuketa and J. A. Harvey, ORNL report, ORNL-3778, 1965.

[7] M. C. Moxon et al., UKAEA Harwell report, AERER7864, 1974.

[8] H. Henriksson et al., in Proceedings of the Inter. Conf. on Nucl. Data for Sci. and Techn.(ND2007) (Nice, Frannce, 2007).

[9] Noguère et al., Nucl. Phys. A 831 (2009).

[10] P. Siegler et al., in Proceedings of the Inter. Conf. on Nucl. Data for Sci. and Techn.(ND2001) (Tsukuba, Japan, 2001); J. Nucl. Sci. Technol. Supp.2, 936 (2002).

[11] N. Janeva, private communication (2007).

[12] A. Borella et al., Nucl. Instrum. Methods Phys. Res. Sect. A 577, 626 (2007).

[13] S. de Jonge, Fast Time Digitizer Type 8514 A, IRMM Geel (1987).

[14] J. Gonzalez, Modular Multi-Parameter Multiplexer (MMPM) hardware description and user guide, IRMM Geel (1997).

[15] A. Borella, AGL2 - User manual, IRMM internal report, 2007.

[16] C. Bastian, in Proceedings of the Inter. Conf. Neutrons in Research and Industry (Crete, Greece, 1996), p. 611.

[17] C. Bastian, AGS Commands, IRMM internal report, 2007.

[18] M. C. Moxon, T. C. Ware and C. J. Dean, REFIT-200910, UKNSF(2010)P243, NEA-0914/08.

[19] M. C. Moxon, Analysis of the $8 \mathrm{eV}$ Doublet in $\mathrm{Hf}$ JEF/DOC-1313.

[20] H. Beer and R.L. Macklin, Phys. Rev. C 26, 1404 (1982).

[21] H. Beer et al., Phys. Rev. C 30, 464 (1984).

[22] M. J. Armishaw and A. J. Cooper, in Proceedings of the Inter. Conf. on Nuclear Criticality Safety, ICNC'07 (St Petersburg, Russia, 2007).

[23] T. C. Ware, PhD Thesis, The University of Birmingham, 2010. 